\title{
Illumina MiSeq sequencing analysis of fungal diversity in stored dates
}

\author{
Ismail M. Al-Bulushi', Muna S. Bani-Uraba ${ }^{1}$, Nejib S. Guizani ${ }^{1}$, Mohammed K. Al-Khusaibi ${ }^{1}$ and Abdullah M. Al-Sadi ${ }^{*}$
}

\begin{abstract}
Background: Date palm has been a major fruit tree in the Middle East over thousands of years, especially in the Arabian Peninsula. Dates are consumed fresh (Rutab) or after partial drying and storage (Tamar) during off-season. The aim of the study was to provide in-depth analysis of fungal communities associated with the skin (outer part) and mesocarp (inner fleshy part) of stored dates (Tamar) of two cultivars (Khenizi and Burny) through the use of Illumina MiSeq sequencing.

Results: The study revealed the dominance of Ascomycota (94\%) in both cultivars, followed by Chytridiomycota (4\%) and Zygomycota (2\%). Among the classes recovered, Eurotiomycetes, Dothideomycetes, Saccharomycetes and Sordariomycetes were the most dominant. A total of 54 fungal species were detected, with species belonging to Penicillium, Alternaria, Cladosporium and Aspergillus comprising more than $60 \%$ of the fungal reads. Some potentially mycotoxin-producing fungi were detected in stored dates, including Aspergillus flavus, A. versicolor and Penicillium citrinum, but their relative abundance was very limited $(<0.5 \%)$. PerMANOVA analysis revealed the presence of insignificant differences in fungal communities between date parts or date cultivars, indicating that fungal species associated with the skin may also be detected in the mesocarp. It also indicates the possible contamination of dates from different cultivars with similar fungal species, even though if they are obtained from different areas.

Conclusion: The analysis shows the presence of different fungal species in dates. This appears to be the first study to report 25 new fungal species in Oman and 28 new fungal species from date fruits. The study discusses the sources of fungi on dates and the presence of potentially mycotoxin producing fungi on date skin and mesocarp.
\end{abstract}

Keywords: Phoenix dactylifera L, Population structure, Fungal diversity, Fungal pathogens, Date palm

\section{Background}

Dates palm (Phoenix dactylifera L.) is one of the oldest and most important fruit trees in the Middle East $[1,2]$. The total worldwide production of dates is around 7.2 million tons, with approximately 5.1 million tons produced by countries in the Middle East [3]. The top 10 producers of dates are Egypt, Iran, Saudi Arabia, Algeria, Iraq, Pakistan, Oman, UAE, Tunisia and Libya. Besides being an important source of vitamins, minerals and other beneficial nutrients, date fruits were the main sources of calories for people living in this part of the world. There are hundreds of date palm cultivars grown in the Middle East, varying in their types from one

\footnotetext{
* Correspondence: alsadi@squ.edu.om; http://www.researchgate. net/profile/Abdullah_Al-Sadi

${ }^{2}$ Department of Crop Sciences, College of Agricultural and Marine Sciences, Sultan Qaboos University, P.O. Box-34, Al-Khod 123, Oman

Full list of author information is available at the end of the article
}

country to the other. In Oman, there are over 200 different date palm cultivars. Khalas, Khenizi, Naghal, Burny, Um Al-Sella, Shahla, Mabsali and Fardh are some of the common cultivars in Oman, occupying more than $50 \%$ of the area devoted for date palm production $[4,5]$.

Date fruits are usually harvested and either consumed directly or dried, packed and consumed at a later stage. The fresh and directly consumed dates are referred to as 'Rutab', while the dried and stored dates are referred to as 'Tamar'. The traditional way of drying dates involves exposing them to direct sun for a certain period of time (few days to weeks). This is followed by packing and storing dates for several months until they are consumed. Since most date palm production in the Middle East is usually within the period from May to October, most people rely on the consumption of fresh dates (Rutab) after harvesting. The duration of consumption of fresh dates is variable, as it depends on the cultivars 
which are grown on a specific location. Some cultivars mature early (e.g. by April to May), while other mature late, sometimes up to October and November. However, after this period, people start consuming the stored dates (Tamar) until the next cycle of date's harvest and production. Some low quality dates are fed to animals because they either come from low quality cultivars or their quality is affected during harvest or storage.

Previous studies reported on the potential contamination of date fruits with some fungal species, including Aspergillus flavus, A. niger, Penicillium chrysogenum and many others [6-10]. These studies raised concerns from the potential contamination of dates with certain mycotoxin-producing fungal species. However, all the previous studies were limited in either being focused on certain fungal types or being dependent on only culture-based approaches for fungal detection [7, 9]. Thus, the amount of information available on the fungal species associated with date fruits is still very limited. This imposes a barrier towards predicting sources of fungal communities and the presence of potentially mycotoxin producing species.

The detection of fungal species in plant material, including date fruits, depended largely on the use of serial dilution or different baiting techniques $[7,8,10]$. However, with the development in molecular techniques, several DNA-based approaches were developed which enabled the detection of several fungal species that are either difficult to grow on synthetic media, or those which are slow growing and usually outgrown by fast growing species. These include the use of pyrosequencing or MiSeq sequencing which made the detection and identification of fungal and bacterial species easy, not only from plant and food material but also from environmental samples such as water and soil [1,11-15].

The main objective of this study was to characterize the main fungal species associated with dates at the Tamar stage. Specific objectives include: (1) to investigate the common fungal species in dates using MiSeq sequencing; and (2) to investigate whether different date parts or date cultivars could differ in their fungal community structure. Understanding fungal diversity in date fruits can help establish a database of the common fungi in these fruits and predict the date fruit parts which are more vulnerable for fungal contamination. It will also help find out the presence of potentially mycotoxinproducing fungi in date fruits.

\section{Methods}

\section{Collection of samples}

The experiment focused on two common date cultivars: Burny and Khenizi. Burny and Khenizi cultivars were grown in Oman in two separate fields, in Ibra and Samail, respectively. Date samples were harvested and immediately exposed to direct sun for approx. 2 weeks. Drying was on the surface of a mat made from dry date leaves. The drying place did not follow any standard hygienic procedures as dates were exposed to natural air without sterilization, which is a usual practice in several places in the Arabian Peninsula. Three different date samples (500 g each) were collected at the Tamar stage from each cultivar after partial drying under the sun. The date samples were healthy without any visual symptoms of any disease. The samples were stored in sterile polyethylene plastic bags at $25-30{ }^{\circ} \mathrm{C}$ for 3 months prior to analysis. The water activity was measured for each sample using a water activity meter (Ro-tronic Hygrolab, Switzerland). Water activity was measured at the beginning of the storage time and 3 months later (at the microbial analysis time). Three individual date fruits were selected from each cultivar. The skin and the mesocarp of each fruit were separated using sterile forceps and scalpel.

\section{DNA extraction}

DNA was extracted from three skin samples and three mesocarp samples of each date cultivar using the CTAB method with slight modifications [16]. The skin and mesocarp of each sample were ground separately using liquid nitrogen. Then, $0.1 \mathrm{~g}$ of date tissue was mixed with $500 \mu \mathrm{l}$ of pre-warmed $2 x$ CTAB buffer $(2 \%$ CTAB, $100 \mathrm{mM}$ Tris pH 8.0, 20 mM EDTA pH 8.0, 1.4 M NaCl, $1 \%$ PVP-40, 0.2\% ß-mercapto-ethanol) and incubated at $65{ }^{\circ} \mathrm{C}$ for $30 \mathrm{~min}$. Then $750 \mu \mathrm{l}$ of phenol: chloroform: isoamyl alcohol (25:24:1) was added to the mixture, vortexed and centrifuged at 10,000 RCF for $15 \mathrm{~min}$. Precooled isopropanol was added to the supernatant and incubated at $-40{ }^{\circ} \mathrm{C}$ for two hr. Then, the mixture was centrifuged at 10,000 RCF for $5 \mathrm{~min}$ and the pellet was washed using $70 \%$ ethanol. The DNA pellet was resuspended in $100 \mu \mathrm{l}$ sterile distilled water and was stored at $-60{ }^{\circ} \mathrm{C}$.

\section{Illumina MiSeq}

Illumina MiSeq was carried out for the six samples from each date cultivar. Amplification of samples was carried out in a two-step process, with the first step to amplify genomic regions of interest and the second step to add sequencing adaptors and sample-specific indices to samples. Construction of the forward primer was done using the Illumina i5 sequencing primer (TCGTCGGCAGCGTCAGATGTGTATAAGAGACAG) and the ITS1F primer (CTTGGTCATTTAGAGGAAGTAA) [17]. The reverse primer was constructed with the Illumina i7 sequencing primer (GTCTCGTGGGCTCGGAGATGTGTATAAGAGACAG) and the ITS2aR primer (GCTGCGTTCTT CATCGATGC) $[1,18]$. The first PCR was conducted in $25 \mu \mathrm{l}$ reaction mixture consisting of $1 \mu \mathrm{l}$ of template 
DNA, $1 \mu \mathrm{l}$ of each $5 \mu \mathrm{M}$ primer and Qiagen HotStar Taq master mix (Qiagen Inc, Valencia, California). The reaction conditions were as follows: an initial denaturation step of $95^{\circ} \mathrm{C}$ for $5 \mathrm{~min}$, then 25 cycles of denaturation at $94^{\circ} \mathrm{C}$ for $30 \mathrm{sec}$, annealing at $54^{\circ} \mathrm{C}$ for $40 \mathrm{sec}$, and extension at $72^{\circ} \mathrm{C}$ for $1 \mathrm{~min}$. The final extension was performed at $72^{\circ} \mathrm{C}$ for $10 \mathrm{~min}$.

Products from the first stage amplification were subjected to a second PCR. Primers for the second PCR were designed based on the Illumina Nextera PCR primers as follows: Forward - AATGATACGGCGACC ACCGAGATCTACAC[i5index]TCGTCGGCAGCGTC and Reverse - CAAGCAGAAGACGGCATACGAGAT[i7index]GTCTCGTGGGCTCGG. The second stage amplification was run the same as the first stage except for 10 cycles.

Amplification products were visualized and then pooled equimolar. Size selection of each pool was done in two rounds followed by quantification using the Quibit 2.0 fluorometer (Life Technologies). Then it was loaded on an Illumina MiSeq (Illumina, Inc. San Diego, California) 2x300 flow cell at 10pM [19].

\section{Biolnformatic analysis}

All sequencing reads were run through Research and Testing Laboratory's (RTL, Lubbock, TX, USA) standard microbial analysis pipeline. The data analysis pipeline consisted of the denoising and chimera detection stage and the microbial diversity analysis stage. In the first stage, denoising was carried out to remove short sequences, singleton sequences, and noisy reads using the USEARCH [20] and UPARSE [21] algorithms. Then, chimera detection was used to remove chimeric sequences using the UCHIME chimera detection software in de novo mode [22]. Finally, the remaining sequences were then corrected per-base to help remove errors in sequencing.

During the diversity analysis stage, all samples were assembled into OTU clusters at $97 \%$ identity using the UPARSE [21] algorithm and then globally aligned using the USEARCH [20] global algorithm against a database of high quality ITS fungal gene sequences from GenBank, compiled by RTL, to determine taxonomic classifications. After OTU selection was performed, a phylogenetic tree was constructed in Newick format from a multiple sequence alignment of the OTUs done in MUSCLE [23, 24] and generated in FastTree [25]. Then fungi were classified at the appropriate taxonomic levels using trimmed taxa which takes confidence values into account at each taxonomic level. Individual analysis was carried out for the percentage of sequences assigned to each fungal phylogenetic level for each pooled sample in order to provide the relative abundance for individual samples. The data were filtered at
97\% similarity threshold. The mean number of raw reads was 33272, 44517, 40643, 54067 before filtering and 26543, 42272, 37194, 51628 after filtering for Burny (mesocarp), Burny (skin), Khenizi (mesocarp) and Khenizi (skin), respectively.

The data were analyzed using the $\mathrm{R}$ software [26]. This included the generation of a rarefaction curve plot of the number of OTUs versus the number of sequences, and estimating Richness and Shannon Diversity indices as explained by Kazeeroni and Al-Sadi [1]. Fungal diversity was also estimated using Bray-Curtis similarities followed by analyzing differences in fungal diversity between groups of samples using 'Permutational Multivariate Analysis of Variance Using Distance Matrices' function ADONIS [27-29].

\section{Statistical analysis}

Differences among samples in the mean value of water activity were analyzed using Tukey's Studentized range test (SAS, SAS Institute Inc., USA).

\section{Results \\ Water activity}

The water activity of the date samples significantly decreased from 0.65 to 0.60 for Burny and 0.62 to 0.59 Khenizi from the first day of storage to 3 months after that (at the day of microbial analysis) $(P<0.05)$.

\section{Fungal diversity estimates}

Analysis showed the presence of variable levels of fungal diversity in the two date cultivars (Burny and Khenizi) and in the skin and mesocarp of date fruits (Fig. 1). No significant differences were observed in Chao Richness estimates between the mesocarp and skin of date fruits and also between the two cultivars (Fig. 2; $P=0.0684$ ), which was due to the slightly high intra-sample diversity within the Burny-skin and Khenizi-mesocarp treatments. Similarly, no significant differences were observed in Shannon diversity between the fruit cultivars or fruit parts (Fig. 3; $P=0.7739$ ).

\section{Dominant fungal groups}

Ascomycota was the most dominant phylum in the skin and mesocarp of the two date cultivars. It accounted for 81 to over $99 \%$ of the fungal reads in the samples. Basidiomycota was present in the skin of both cultivars and in the mesocarp of Khenizi. Chytridiomycota accounted for $16 \%$ of the fungal populations in the mesocarp of Khenizi (Fig. 4).

Eurotiomycetes was the most dominant fungal class in the samples, followed by Dothideomycetes, Saccharomycetes and Sordariomycetes (Fig. 4). Eurotiomycetes, Dothideomycetes and Sordariomycetes were detected in all four samples, while the remaining classes were 


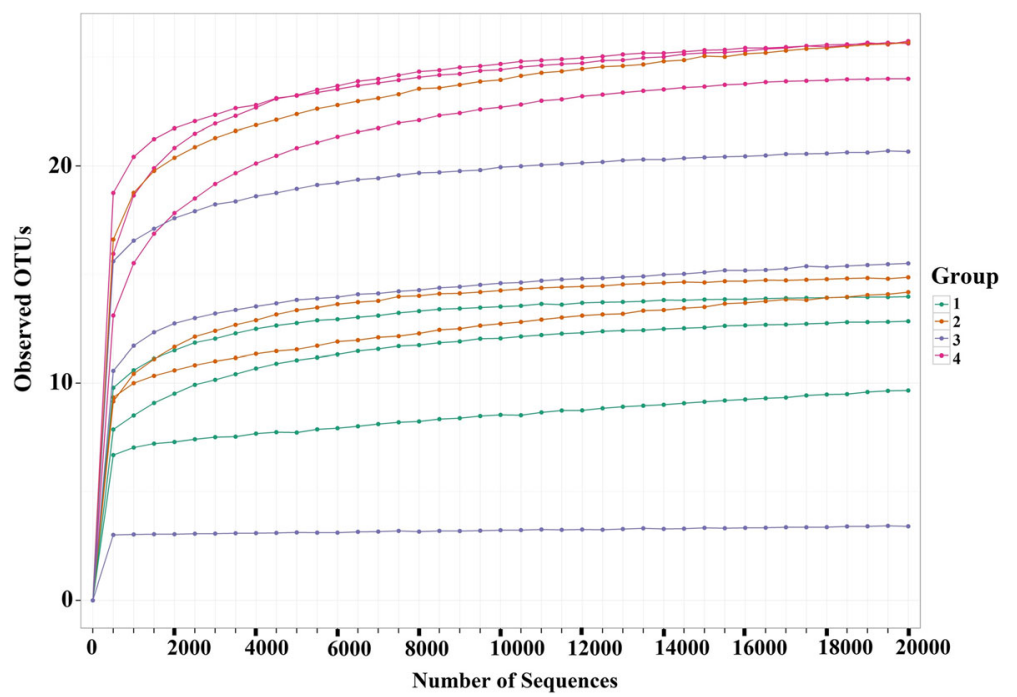

Fig. 1 Rarefaction plot of species richness, subsampling from 0 to 20,000 reads in increments of 500 reads. Groups 1, 2, 3 and 4 represent Burny (mesocarp), Burny (skin), Khenizi (mesocarp) and Khenizi (skin), respectively

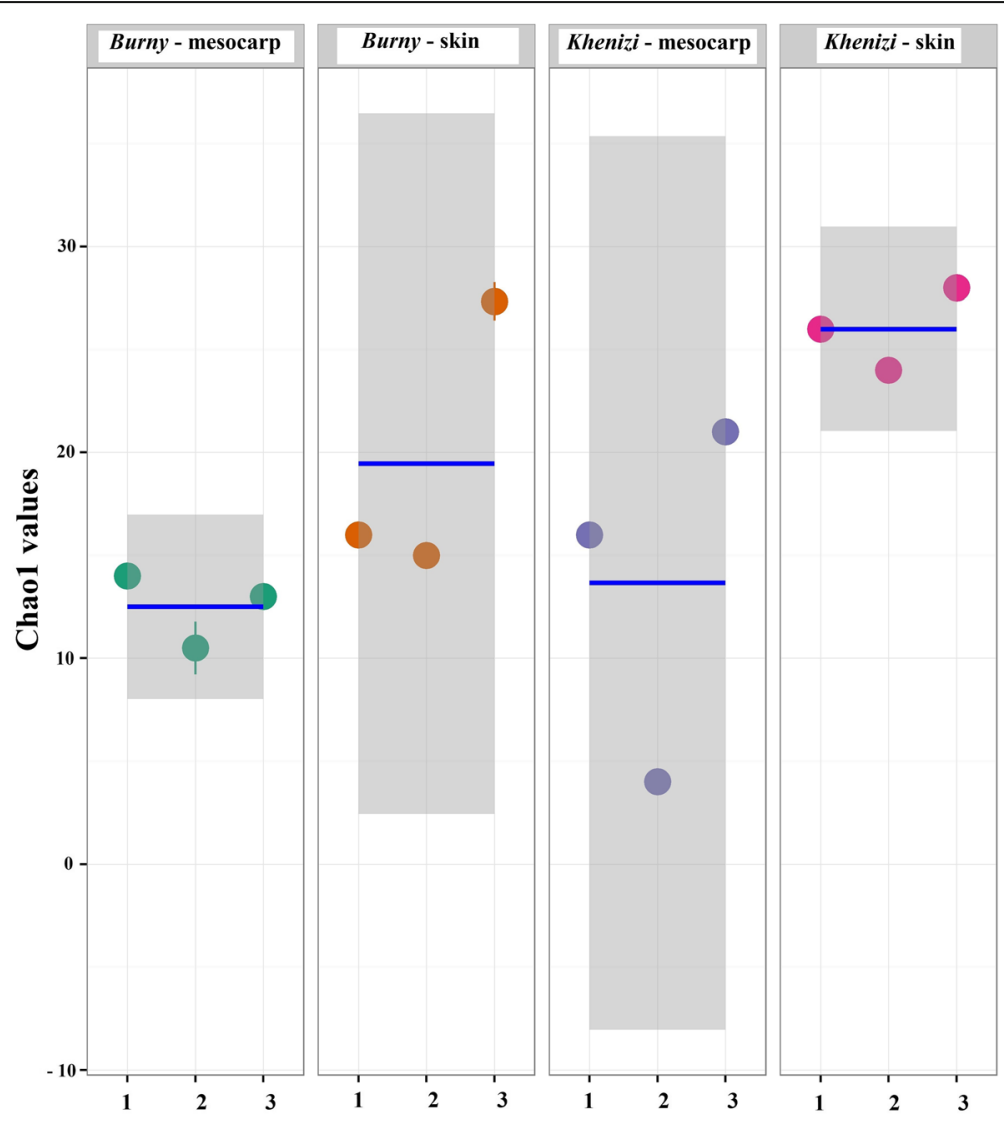

Fig. $\mathbf{2}$ Chao 1 richness estimates for the four date samples. The mean value (line) and confidence interval (shaded) in each group also are illustrated 


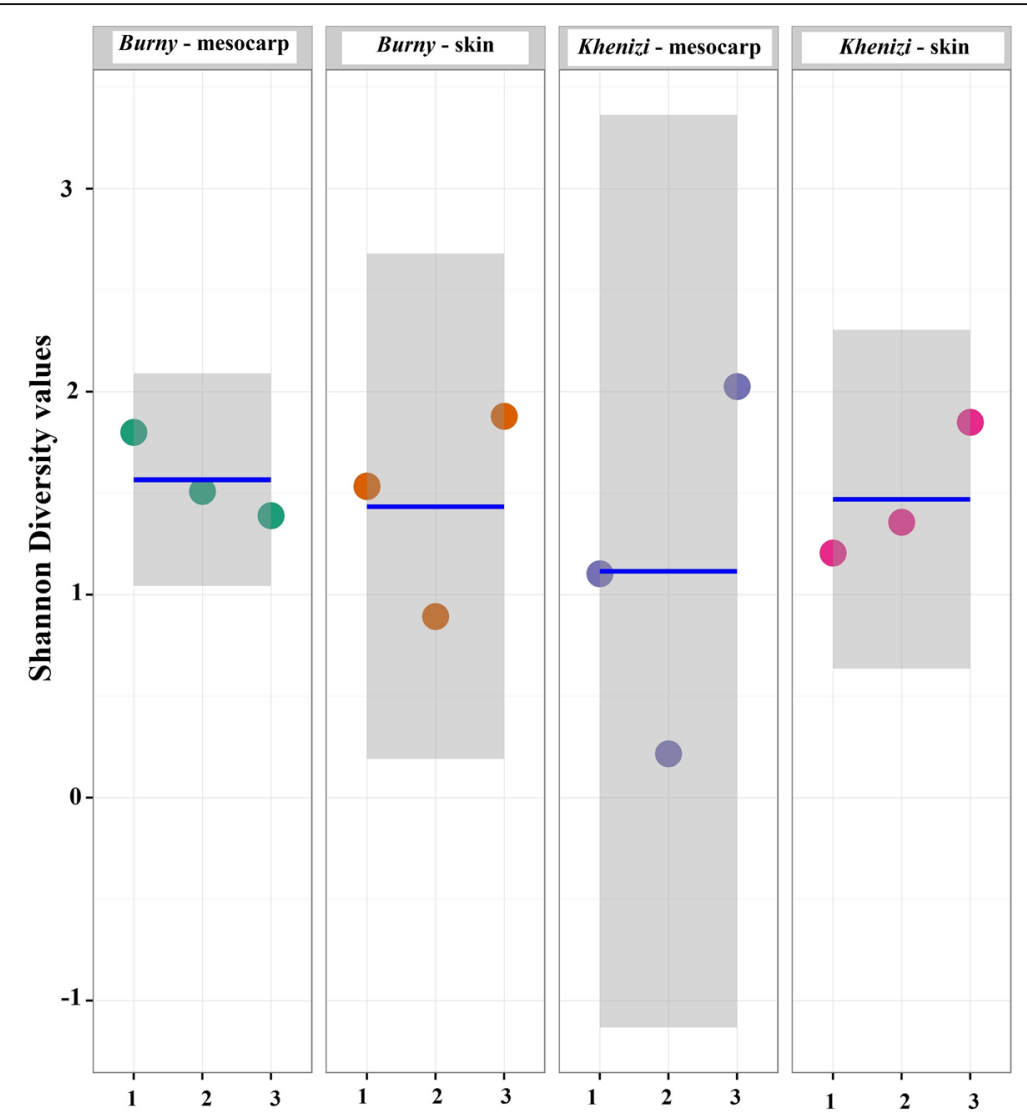

Fig. 3 Shannon diversity for the four date samples. The mean value (line) and confidence interval (shaded) in each group also are illustrated

detected in some of the samples. Tremellomycetes was detected in the skin and mesocarp of Khenizi but not in Burny.

Analysis of fungal species in the date samples revealed the presence of 54 different fungal species. Eleven of the fungal taxa could not be resolved to the genus or species level, nine were only resolved to the genus level while 34 were identified to the species level (Fig. 5; Table 1). Penicillium, Alternaria, Cladosporium and Aspergillus species were the most common in most samples. Penicillium griseofulvum was the most common fungal species in all samples, making up 13 to $42 \%$ of the total fungal reads. This was followed by Alternaria sp., Aspergillus tubingensis, Fusarium sp. and Cladosporium cladosporioides.

Twelve fungal species were detected from the skin and mesocarp of Burny, 17 were detected in skin but not the mesocarp and two were detected in mesocarp but not in skin. In Khenizi, 17 fungal species occurred in both the skin and mesocarp tissues, 19 occurred only in the skin and 11 occurred only in the mesocarp (Table 1). Trichoderma asperellum, Aspergillus versicolor and Pichia sp were detected only in the mesocarp and skin of Khenizi but not in Burny. Aspergillus flavus and Zygosaccharomyces rouxii were detected only in the skin of Khenizi and Burny cultivars (Table 1). Some fungal species were detected for the first time in date fruits or in Oman (Table 1).

\section{Analysis of community composition across samples}

PerMANOVA analysis based on Bray-Curtis distances indicated the presence of insignificant differences in the fungal community structure between the mesocarp and skin of Burny $\left(R^{2}=0.346, P=0.150\right)$ and Khenizi $\left(R^{2}=\right.$ $0.310, P=0.150)$ cultivars. Also, no significant differences were observed in the fungal community structure between the Burny and Khenizi cultivars (Table 2).

\section{Discussion}

Ascomycota was the most common phylum in the skin and mesocarp of dates. Ascomycota is a very common fungal phylum, previously reported to dominate fungal groups in plant tissues and different soil types and fertilizers $[1,7,11,13]$. Previous studies on date fruits using culture-based techniques also revealed that Ascomycota is the dominant phylum in date fruits $[6,8]$. Eurotiomycetes was the most dominant class in date fruits, mainly because it contains two of the most dominant genera in date fruits: Penicillium and Aspergillus. 


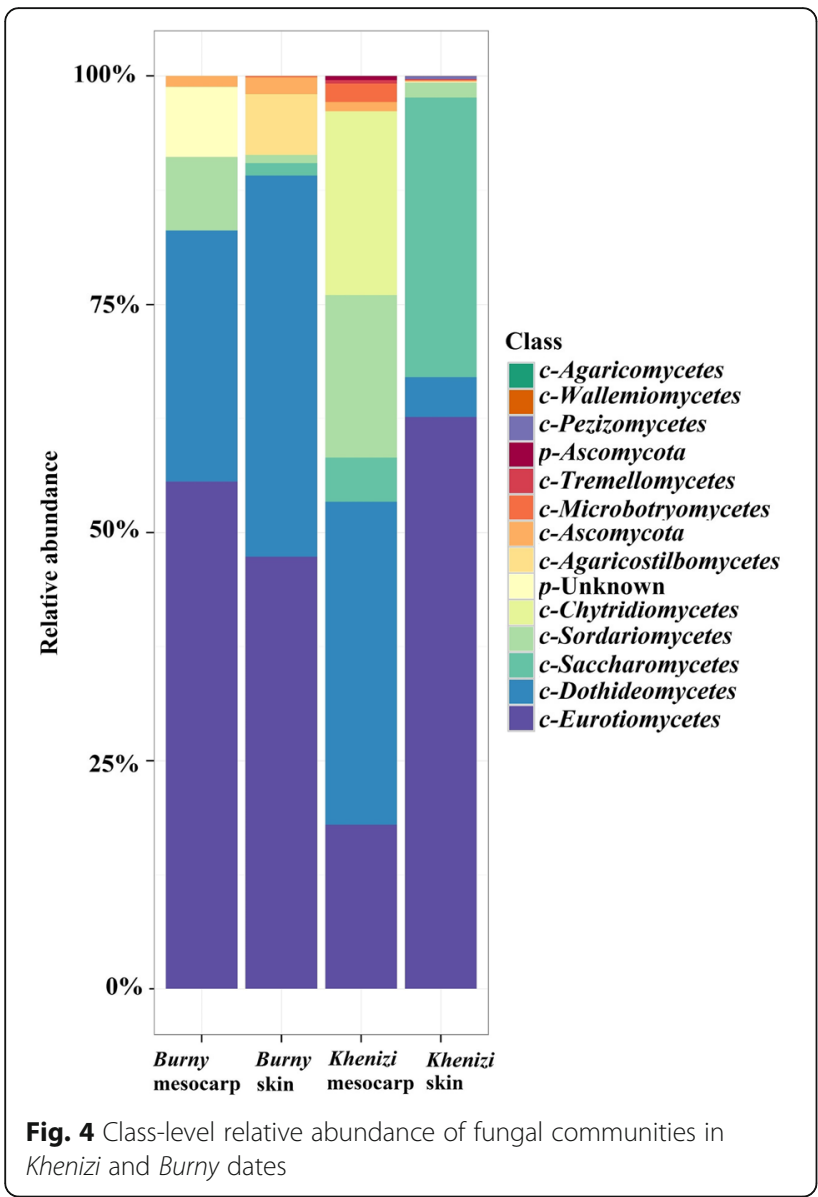

Penicillium, Alternaria, Aspergillus and Cladosporium were the most dominant fungal genera in date fruits, comprising more than $60 \%$ of the genera observed in date fruits. These fungi, especially Penicillium and Aspergillus, are very common airborne fungi that produce thousands of spores and they are common on date fruits. Previous studies reported the association of Alternaria spp., Aspergillus spp., Cladosporium spp, Dreschlera spicifera, Eurotium amstelodami, E. chevalieri, Fusarium spp., Mucor racemosus, Myrothecium verrucaria, Penicillium spp., Rhizopus stolonifer, Ulocladium atrum and others with date fruits [6-10, 30-32]. In the current study, 28 fungal species appear to be reported for the first time on date fruits, of which 12 were found on skin and mesocarp, 15 were only on skin and one was only in the mesocarp. This indicates that date fruit, especially the outer skin, is exposed to several fungal species.

The majority of the detected fungal taxa in date fruits are either spoilage fungi (e.g. Alternaria spp.) or saprophytes (e.g. Trichoderma asperellum). Although date palm is known to be affected by several fungal diseases including bayoud disease (Fusarium oxysporum f.sp. albedenis) and black scorch (Ceratocystis radicicola) [4, 33], the causal agents of these diseases

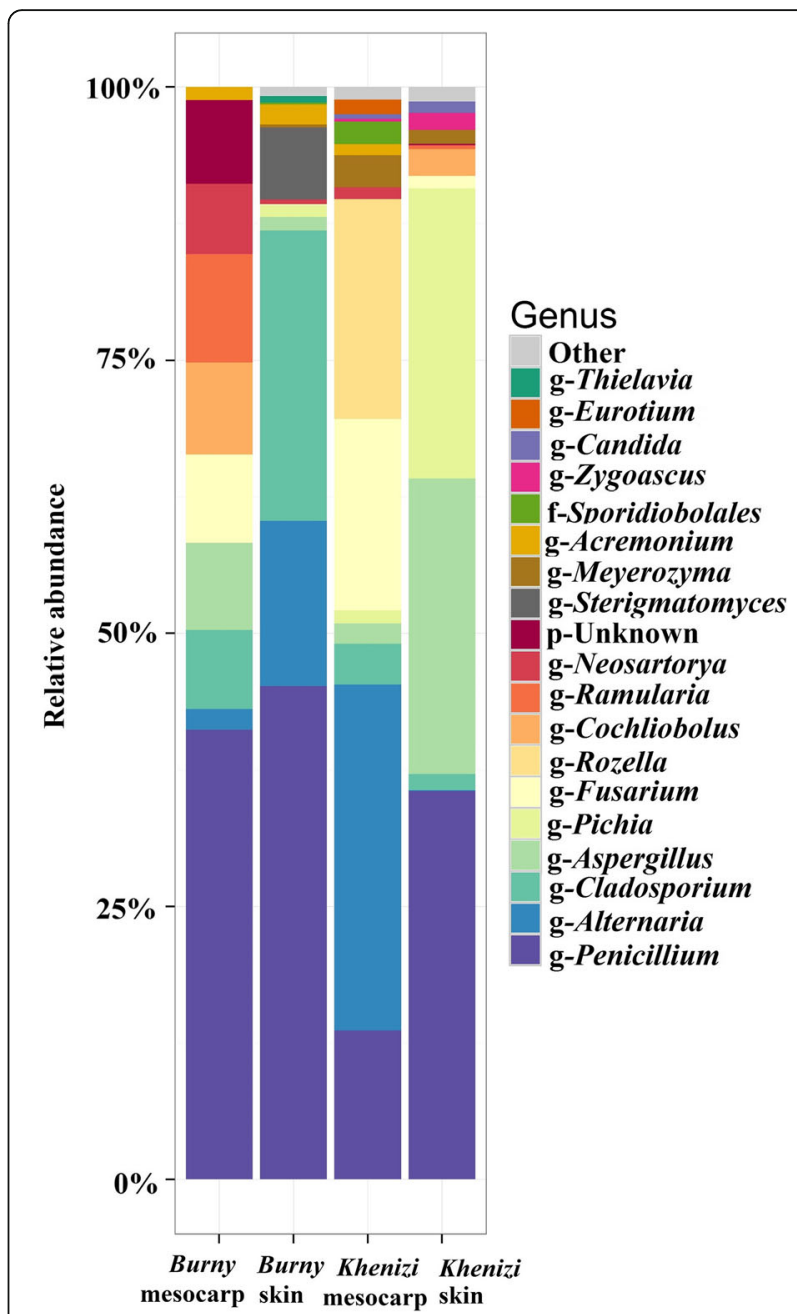

Fig. 5 Relative abundance of the 19 most dominant fungal genera in Khenizi and Burny dates

were not detected in date fruits. Three potentially mycotoxin producing fungi were detected on date fruits, namely Aspergillus flavus, A. versicolor and Penicillium citrinum. Although several reports indicated that these are potential mycotoxin-producing fungi in several crops and food types [30, 34-38], our findings showed that they were found to make up less than $0.5 \%$ of the total fungal reads in date fruits. In addition, A. flavus was only detected in the skin of both cultivars, not in the fleshy part, which may impose less risk on humans. However, more studies should be done in the future to examine the potential presence of mycotoxin and mycotoxin-producing fungi in dates at different stages of maturation and from different cultivars. In addition, it is unclear whether many of the several fungal species detected in this study could impose a potential risk to humans after consuming contaminated dates or they have a possible role in chemical changes in stored date fruits. Future 
Table 1 Frequency of occurrence of different fungal isolates in the skin and mesocarp of Burny and Khenizi date cultivars

\begin{tabular}{|c|c|c|c|c|}
\hline \multirow[b]{2}{*}{ Species } & \multicolumn{2}{|l|}{ Burny } & \multicolumn{2}{|l|}{ Khenizi } \\
\hline & Mesocarp & Skin & Mesocarp & Skin \\
\hline Penicillium griseofulvum* & 42.132 & 40.873 & 12.511 & 26.625 \\
\hline Alternaria sp & 1.698 & 20.16 & 40.983 & 0.168 \\
\hline Aspergillus tubingensis* & 7.344 & 1.105 & 1.299 & 37.294 \\
\hline Fusarium sp & 8.056 & 0.077 & 14.909 & 2.366 \\
\hline Cladosporium cladosporioides & 3.07 & 16.768 & 2.421 & 1.823 \\
\hline Pichia kudriavzeviï* & 0 & 1.44 & 0.99 & 16.474 \\
\hline Rozella sp & 0 & 0.004 & 16.612 & 0 \\
\hline Cochliobolus sp & 10.004 & 0.002 & 0 & 5.143 \\
\hline Unknown 1 & 3.184 & 7.221 & 0.635 & 0.504 \\
\hline Ramularia eucalypti* & 8.891 & 0 & 0 & 0.688 \\
\hline Neosartorya pseudofischeri* & 5.848 & 0.572 & 0.953 & 0.129 \\
\hline Unknown 2 & 7.004 & 0 & 0 & 0.048 \\
\hline Sterigmatomyces elviae* & 0 & 5.651 & 0 & 0 \\
\hline Meyerozyma guilliermondii* & 0 & 0.181 & 2.587 & 2.227 \\
\hline Acremonium implicatum* & 1.432 & 1.58 & 0.761 & 0 \\
\hline Cladosporium perangustum* & 1.296 & 1.385 & 0.209 & 0.471 \\
\hline Zygoascus meyerae* & 0 & 0.002 & 0.319 & 2.243 \\
\hline Unknown 3 & 0 & 0.134 & 1.786 & 0 \\
\hline Candida tropicalis* & 0 & 0 & 0 & 1.195 \\
\hline Eurotium amstelodami & 0 & 0 & 1.174 & 0 \\
\hline Pichia sp & 0 & 0 & 0.014 & 1.001 \\
\hline Cephaliophora tropica* & 0 & 0 & 0 & 0.723 \\
\hline Unknown 4 & 0 & 0.513 & 0 & 0 \\
\hline Exophiala oligosperma* & 0 & 0.432 & 0.049 & 0 \\
\hline Penicillium pinophilum* & 0 & 0.438 & 0 & 0 \\
\hline Cladosporium sphaerospermum* & 0 & 0.428 & 0 & 0 \\
\hline Alternaria alternata & 0.001 & 0.4 & 0.001 & 0.003 \\
\hline Aspergillus versicolor & 0 & 0 & 0.32 & 0.065 \\
\hline Unknown 5 & 0 & 0 & 0.376 & 0 \\
\hline Unknown 6 & 0 & 0 & 0.356 & 0 \\
\hline Hannaella sinensis* & 0 & 0 & 0.335 & 0 \\
\hline Aspergillus flavus & 0 & 0.266 & 0 & 0.057 \\
\hline Unknown 7 & 0 & 0 & 0 & 0.221 \\
\hline Nigrospora sp & 0 & 0 & 0 & 0.192 \\
\hline Myrothecium inundatum* & 0 & 0.177 & 0 & 0 \\
\hline Acremonium sp & 0 & 0 & 0.136 & 0 \\
\hline Unknown 8 & 0 & 0 & 0.118 & 0 \\
\hline Trichoderma asperellum* & 0 & 0 & 0.109 & 0.008 \\
\hline Penicillium citrinum* & 0.041 & 0.003 & 0.032 & 0.008 \\
\hline Cladosporium sp & 0 & 0.076 & 0 & 0 \\
\hline Kodamaea ohmeri* & 0 & 0 & 0 & 0.073 \\
\hline Unknown 9 & 0 & 0 & 0 & 0.068 \\
\hline Zygosaccharomyces rouxii* & 0 & 0.053 & 0 & 0.005 \\
\hline
\end{tabular}


Table 1 Frequency of occurrence of different fungal isolates in the skin and mesocarp of Burny and Khenizi date cultivars (Continued)

\begin{tabular}{|c|c|c|c|c|}
\hline Rhodosporidium kratochvilovae* & 0 & 0 & 0 & 0.052 \\
\hline Symbiotaphrina kochii & 0 & 0 & 0 & 0.05 \\
\hline Unknown 10 & 0 & 0.046 & 0 & 0.003 \\
\hline Cryptococcus albidus* & 0 & 0 & 0 & 0.036 \\
\hline Candida pimensis* & 0 & 0 & 0 & 0.015 \\
\hline Phoma sp & 0 & 0.01 & 0 & 0 \\
\hline Melanocarpus albomyces* & 0 & 0 & 0 & 0.008 \\
\hline Rhodotorula mucilaginosa* & 0 & 0 & 0 & 0.008 \\
\hline Wallemia sebi* & 0 & 0 & 0 & 0.006 \\
\hline Penicillium corylophilum & 0 & 0.004 & 0 & 0 \\
\hline Unknown 11 & 0 & 0 & 0.002 & 0 \\
\hline
\end{tabular}

Species in bold are reported in this study for the first time in Oman, while species with $\left(^{*}\right)$ symbol are reported for the first time on date fruits. Unknown fungi could not be resolved to the species level. Full data are available through this link http://rtlgenomics.com/ (Project ID: Al-Sadi 4317 Fungal)

experiments on these fungi could reveal some of their risks or benefits.

Although several fungal species were detected in dates at the Tamar stage, no spoilage was observed in any of the date fruits which were subject to analysis. As opposite to dates at the Rutab stage which usually spoil quickly because of the high water activity, spoilage of Tamar is not common mainly because of the reduced water activity. Findings from this study revealed that water activity in the stored dates decreased for Burny and Khenizi dates from 0.64 to 0.62 at the storage time to 0.61 and 0.59 , respectively 3 months later. Previous studies reported that many of the food spoilage fungi usually grow at water activity ranges from 0.7 to 0.94 [39].

PerMANOVA analysis indicated that fungal communities in the skin of dates are not significantly different from the communities in the mesocarp for both cultivars. This may suggest that fungal species contaminating the outer part of dates' fruit (skin) may have the ability to grow into the mesocarp. In our study, 39\% and 35\% of the fungal species contaminating the skin were also detected in the mesocarp of Burny and Khenizi cultivars, respectively. Contamination of the dates' skin and mesocarp with the same fungal species could have occurred while dates were on trees or immediately after harvest. This is because drying of dates can reduce water activity to levels that may not favor fungal growth $[6-8,39]$.
This may impose a problem to consumers, as even if they remove the skin of dates, they may not get rid of all fungi because many of the fungi are in the fleshy part, the mesocarp. It is therefore important to find out the stage at which contamination occurs to help reduce fungal contamination in dates.

Analysis indicated that 23 unique fungal species were observed in Khenizi but not in Burny, while 7 unique fungal species were observed in Burny but not in Khenizi. Also, Penicillium griseofulvum was found to make up $41-42 \%$ of the species in Burny compared to $13-27 \%$ of the species in Khenizi. However, PerMANOVA analyses did not reveal any significant differences in fungal diversity between the two date cultivars $(P>0.05)$. Although the dates from the two cultivars were obtained from two different areas, there appears to be no effect of location or cultivars on the fungal community structure of date fruits.

The presence of different fungal species in date fruits as shown by the analyses of alpha diversity (Shannon index, richness estimates) and beta diversity (perMANOVA analysis of Bray-Curtis similarities) raises questions concerning the sources of these fungi. The low level of water activity in dates may lower the chance for dates to be infected at the drying/storage stage. However, the ripening stage of dates is the stage at which contamination by fungi may occur $[8,31]$. Since our study did not evaluate this stage, a future study on the

Table 2 Effect of date parts and date cultivars on fungal diversity revealed using PerMANOVA analysis

\begin{tabular}{lllll}
\hline Parameter & Treatment & F model & $R^{2}$ & $P$ adjusted \\
\hline Date part & Skin X mesocarp (Burny cultivar) & 2.113499 & 0.34571 & 0.150 \\
& Skin X mesocarp (Khenizi cultivar) & 1.799876 & 0.31033 & 0.150 \\
Cultivar & Burny X Khenizi (Mesocarp) & 1.621053 & 0.28839 & 0.150 \\
& Burny X Khenizi (Skin) & 2.899156 & 0.420219 & 0.150 \\
\hline
\end{tabular}


possible contamination of dates at different stages of maturation and storage may reveal the stage at which contamination is at high. This may help reduce the chance of date contamination with fungi.

\section{Conclusion}

Alpha-based analyses of fungal diversity in date palm fruits at the Tamar stage indicated the presence of different fungal species. The study appears to be the first report of 25 fungal species in Oman and 28 fungal species on date fruits, with some species being potential producers of mycotoxins. Beta analysis of fungal communities showed that they are not related to specific date cultivars or date part (skin and mesocarp), indicating the possible contamination of date cultivars and date parts with the same species of fungi. Future studies should address the source of these fungi in date fruits. They should also address fungal contamination in dates at different stages of maturation/drying and the role of fungi in date spoilage, especially at the Rutab stage. In addition, attention should be given to evaluating the effect of date processing on reducing contamination of dates with harmful fungi.

\section{Abbreviations \\ CTAB: Cetyltrimethylammonium bromide; ITS: Internal transcribed spacer; OUT: Operational taxonomic unit}

\section{Acknowledgments}

Thanks are due to Mr. Issa Al-Mahmooli and Mr. Waleed Al Busaidi for help in DNA extraction and to Jeremy Wilkinson for help in data analysis.

\section{Funding}

Authors would like to acknowledge Sultan Qaboos University, The Research Council and Oman Animal and Plant Genetic Resources Center for financial support of the study through the project EG/AGR/CROP/16/01.

\section{Availability of data and materials}

All data of species detected in this study are presented in Table 1.

\section{Author's contributions}

$I A, M B, N G, M A$ and $A M A$ planned the study; MB and AMA carried out the work; IA, MB and $A M A$ analyzed data; $I A, M B, N G, M A$ and $A M A$ wrote the manuscript; IA, MB, NG, MA and AMA revised and approved the final version of the paper.

\section{Competing interests}

The authors declare that the research was conducted in the absence of any commercial or financial relationships that could be construed as a potential conflict of interest. The authors declare that they have no competing interests.

\section{Consent for publication}

Not applicable.

Ethics approval and consent to participate

Not applicable.

\section{Publisher's Note}

Springer Nature remains neutral with regard to jurisdictional claims in published maps and institutional affiliations.

\section{Author details}

'Department of Food Science and Nutrition, College of Agricultural and Marine Sciences, Sultan Qaboos University, P.O. Box-34, Al-Khod 123, Oman. ${ }^{2}$ Department of Crop Sciences, College of Agricultural and Marine Sciences, Sultan Qaboos University, P.O. Box-34, Al-Khod 123, Oman.

Received: 15 November 2016 Accepted: 17 March 2017

Published online: 27 March 2017

\section{References}

1. Kazeeroni EA, Al-Sadi AM. 454-pyrosequencing reveals variable fungal diversity across farming systems. Front Plant Sci. 2016;7:314.

2. Chao CT, Krueger RR. The date palm (Phoenix dactylifera L.): Overview of biology, uses, and cultivation. HortSci. 2007;42(5):1077-82.

3. FAOSTAT. [http://www.fao.org/faostat/en/\#data/QC/visualize]

4. Al-Sadi AM, Al-Jabri AH, Al-Mazroui SS, Al-Mahmooli IH. Characterization and pathogenicity of fungi and oomycetes associated with root diseases of date palms in Oman. Crop Protect. 2012;37:1-6.

5. Al-Yahyai $\mathrm{R}$, Khan MM. Date palm status and perspective in oman. In: Date Palm Genetic Resources and Utilization: Volume 2: Asia and Europe. 2015. p. 207-40.

6. Gherbawy YA, Elhariry HM, Bahobial AAS. Mycobiota and mycotoxins (aflatoxins and ochratoxin) associated with some Saudi date palm fruits. Foodborne Pathog Dis, 2012:9(6):561-7.

7. Al-Sheikh H. Date-palm fruit spoilage and seed-borne fungi of Saudi Arabia. Res J Microbiol. 2009:4(5):208-13.

8. Shenasi M, Aidoo KE, Candlish AAG. Microflora of date fruits and production of aflatoxins at various stages of maturation. Int J Food Microbiol. 2002; 79(1-2):113-9.

9. Atia MMM. Efficiency of physical treatments and essential oils in controlling fungi associated with some stored date palm fruits. Aust J Basic Appl Sci. 2011;5(6):1572-80.

10. Jogee SP, Ingle AP, Gupta IR, Bonde SR, Rai MK. Detection and management of mycotoxigenic fungi in nuts and dry fruits. Acta Hortic. 2012;963:69-77.

11. Al-Mazroui SS, Al-Sadi AM. 454 pyrosequencing and direct plating reveal high fungal diversity and dominance by saprophytic species in organic compost. Int J Agric Biol. 2016;18(1):98-102.

12. Al-Sadi AM, Al-Mazroui SS, Phillips AJL. Evaluation of culture-based techniques and 454 pyrosequencing for the analysis of fungal diversity in potting media and organic fertilizers. J Appl Microbiol. 2015;119(2):500-9.

13. Abed RMM, Al-Sadi AM, Al-Shehi M, Al-Hinai S, Robinson MD. Diversity of free-living and lichenized fungal communities in biological soil crusts of the Sultanate of Oman and their role in improving soil properties. Soil Biol Biochem. 2013;57:695-705.

14. Huang X, Liu L, Wen T, Zhu R, Zhang J, Cai Z. Illumina MiSeq investigations on the changes of microbial community in the Fusarium oxysporum f.sp. cubense infected soil during and after reductive soil disinfestation. Microbiol Res. 2015;181:33-42.

15. Qi X, Liu B, Song Q, Zou B, Bu Y, Wu H, Ding L, Zhou G. Assessing fungal population in soil planted with Cry1 Ac and CPTI transgenic cotton and its conventional parental line using $18 \mathrm{~S}$ and ITS rDNA sequences over four seasons. Front Plant Sci. 2016;7:1023.

16. Doyle J, Doyle JL. Isolation of plant DNA from fresh tissue. Focus. 1990;12: 13-5.

17. Gardes M, Bruns T. ITS primers with enhanced specificity for basidiomycetes - application to the identification of mycorrhizae and rusts. Mol Ecol. 1993; 2:113-8.

18. White TJ, Bruns T, Lee S, Taylor J. Amplification and direct sequencing of fungal ribosomal RNA genes for phylogenetics. In: Innis MA, Gelfand DH, Sninsky JJ, White TJ, editors. PCR protocols: A Guide to Methods and Applications. New York: Academic; 1990. p. 315-22.

19. Ruff S, Kuhfuss H, Wegener G, Lott C, Ramette A, Wiedling J, Knittel K, Weber M. Methane seep in shallow-water permeable sediment harbors high diversity of anaerobic methanotrophic communities, Elba, Italy. Front Microbiol. 2016;7:374.

20. Edgar RC. Search and clustering orders of magnitude faster than BLAST. Bioinformatics. 2010;26:2460-1.

21. Edgar RC. UPARSE: highly accurate OTU sequences from microbial amplicon reads. Nat Methods. 2013;10:996-8. 
22. Edgar RC, Haas BJ, Clemente JC, Quince C, Knight R. UCHIME improves sensitivity and speed of chimera detection. Oxford Journal of Bioinformatics. 2011;27:2194-200.

23. Edgar RC. MUSCLE: multiple sequence alignment with high accuracy and high throughput. Nucleic Acids Res. 2004;32:1792-7.

24. Edgar RC. MUSCLE: a multiple sequence alignment method with reduced time and space complexity. BMC Bioinformatics. 2004;5:1.

25. Price M, Dehal P, Arkin A. FastTree 2-approximately maximum-likelihood trees for large alignments. Plos One. 2010;5, e9490.

26. Team RDC. R: A Language and Environment for Statistical Computing. Vienna: R Foundation for Statistical Computing; 2011.

27. Oksanen J, Blanchet FG, Kindt R, Legendre P, O'Hara RB, Simpson GL, Solymos P, Henry M, Stevens H, Wagner H. VEGAN: Community Ecology Package. 2011, R package version:1.17-18.

28. Hartmann M, Frey B, Mayer J, Mäder P, Widmer F. Distinct soil microbial diversity under long-term organic and conventional farming. ISME J. 2015; 9(5):1177-94.

29. Moll J, Hoppe B, König S, Wubet T, Buscot F, Krüger D. Spatial distribution of fungal communities in an arable soil. Plos One. 2016;11, e0148130.

30. Abbas HK, Shier WT, Plasencia J, Weaver MA, Bellaloui N, Kotowicz JK, Butler AM, Accinelli C, de la Torre-Hernandez ME, Zablotowicz RM. Mycotoxin contamination in corn smut (Ustilago maydis) galls in the field and in the commercial food products. Food Control. 2017;71:57-63.

31. Shenasi M, Candlish AAG, Aidoo KE. The production of aflatoxins in fresh date fruits and under simulated storage conditions. J Sci Food Agric. 2002; 82(8):848-53.

32. Aidoo KE, Tester RF, Morrison JE, MacFarlane D. The composition and microbial quality of pre-packed dates purchased in Greater Glasgow. Int J Food Sci Technol. 1996;31(5):433-8.

33. Siala R, Chobba IB, Vallaeys T, Triki MA, Jrad M, Cheffi M, Ayedi I, Elleuch A, Nemsi A, Cerqueira F, et al. Analysis of the cultivable endophytic bacterial diversity in the date palm (Phoenix dactylifera L.) and evaluation of its antagonistic potential against pathogenic Fusarium species that cause date palm bayound disease. Journal of Applied and Environmental Microbiology. 2016:4(5):93-104.

34. Kumar M, Dwivedi P, Sharma AK, Sankar M, Patil RD, Singh ND. Apoptosis and lipid peroxidation in ochratoxin A- and citrinin-induced nephrotoxicity in rabbits. Toxicol Ind Health. 2014;30(1):90-8.

35. Kocić-Tanackov SD, Dimić GR, Lević JT, Pejin DJ, Pejin JD, Jajić IM. Occurrence of potentially toxigenic mould species in fresh salads of different kinds of ready-for-use vegetables. Acta Periodica Technologica. 2010;41:33-45

36. Engelhart S, Loock A, Skutlarek D, Sagunski H, Lommel A, Färber $H$, Exner M. Occurrence of toxigenic Aspergillus versicolor isolates and sterigmatocystin in carpet dust from damp indoor environments. Appl Environ Microbiol. 2002;68(8):3886-90.

37. Mills JT. Mycotoxins and toxigenic fungi on cereal grains in western Canada. Can J Physiol Pharmacol. 1990;68(7):982-6.

38. Yogendrarajah $P$, Vermeulen A, Jacxsens $L$, Mavromichali E, De Saeger $S$, De Meulenaer B, Devlieghere F. Mycotoxin production and predictive modelling kinetics on the growth of Aspergillus flavus and Aspergillus parasiticus isolates in whole black peppercorns (Piper nigrum L). Int J Food Microbiol. 2016;228:44-57.

39. Jay J, Loessner M, Golden D. Modern Food Microbiology. 7th ed. New York: Springer Science and Business Media; 2005.

\section{Submit your next manuscript to BioMed Central and we will help you at every step:}

- We accept pre-submission inquiries

- Our selector tool helps you to find the most relevant journal

- We provide round the clock customer support

- Convenient online submission

- Thorough peer review

- Inclusion in PubMed and all major indexing services

- Maximum visibility for your research

Submit your manuscript at www.biomedcentral.com/submit
) Biomed Central 